\title{
Low numbers of blood and salivary natural killer cells are associated with a better response to belimumab in primary Sjögren's syndrome: results of the BELISS study
}

Raphaèle Seror ${ }^{1,2^{*}+}$, Gaétane Nocturne ${ }^{1 \dagger}$, Thierry Lazure ${ }^{3}$, Houria Hendel-Chavez ${ }^{1,4}$, Frédéric Desmoulins², Rakiba Belkhir ${ }^{2}$, Philippe Ravaud ${ }^{5}$, Mohcine Benbijja ${ }^{2}$, Vichnou Poirier-Colame ${ }^{6}$, Yacine Taoufik ${ }^{1,4}$ and Xavier Mariette ${ }^{1,2^{*}}$

\begin{abstract}
Introduction: In this study, we sought to address changes in blood lymphocyte subpopulations and labial salivary gland (LSG) inflammation after belimumab treatment in patients with primary Sjögren's syndrome (pSS) and to identify predictors of response to treatment.

Methods: Sequential blood lymphocyte subsets and LSG biopsies were analysed between week 0 (W0) and W28 in 15 patients with pSS treated with belimumab. Systemic response to treatment was defined as a decrease in the European League Against Rheumatism Sjögren's Syndrome Disease Activity Index score of $\geq 3$ points at W28.

Results: After belimumab, we observed a decrease in blood B lymphocytes primarily involving CD27-negative/ immunoglobulin D-positive naïve B cells ( $(=0.008$ ). Lymphocytic sialadenitis (focus score $>1$ ) that was present in 12 patients $(80.0 \%)$ before belimumab treatment became negative in 5 of them after treatment $(p=0.03)$. The median (interquartile range) LSG B-cell/T-cell ratio decreased from $0.58(0.5-0.67)$ to $0.50(0.5-0.5)(p=0.06)$. B-cell activating factor (BAFF) staining was detected in 11 (78.6\%) of 14 patients before belimumab treatment compared with 7 (50.0\%) of 14 after belimumab therapy $(p=0.10)$. The median percentage of BAFF-positive cells in foci significantly decreased from $27.5 \%(10-40)$ to $5 \%(0-20)(p=0.03)$. A systemic response was achieved in six patients (40\%). The only predictor of response was the presence of a low number of natural killer (NK) cells, both in blood (8.5\% [7-10] vs $11 \%$ [9-21]; $p=0.04)$ and in LSG (20.6/ $\mathrm{mm}^{3}$ [20.0-21.4] vs 30.0/ $\mathrm{mm}^{3}$ [25.0-100.0], $\left.p=0.003\right)$. Serum BAFF levels did not influence response to treatment.
\end{abstract}

Conclusions: Low blood and salivary NK cell numbers are associated with a better response to belimumab. This suggests that two distinct subsets of pSS may exist: one with a predominant type I interferon (IFN)-BAFF-B-cell axis, representing good responders to belimumab; and one with a predominant type II IFN-NK cell axis, representing non-responders.

Trial registration: ClinicalTrials.gov identifier: NCT01160666. Registered 9 July 2010.

\footnotetext{
*Correspondence: raphaele.se@gmail.com; xavier.mariette@bct.aphp.fr

${ }^{\dagger}$ Equal contributors

'Université Paris-Sud, Center of Research on Immunology of Viral and Autoimmune diseases (IMVA), INSERM U1184, Le Kremlin Bicêtre, France

${ }^{2}$ Université Paris-Sud, Assistance Publique-Hôpitaux de Paris (AP-HP), Service de Rhumatologie, Hôpitaux Universitaires Paris-Sud, Hôpital Bicêtre, 78 rue

du Général Leclerc, 94275 Le Kremlin Bicêtre, France

Full list of author information is available at the end of the article
}

(c) 2015 Seror et al. Open Access This article is distributed under the terms of the Creative Commons Attribution 4.0 International License (http://creativecommons.org/licenses/by/4.0/, which permits unrestricted use, distribution, and reproduction in any medium, provided you give appropriate credit to the original author(s) and the source, provide a link to the Creative Commons license, and indicate if changes were made. The Creative Commons Public Domain Dedication waiver (http://creativecommons.org/publicdomain/zero/1.0/) applies to the data made available in this article, unless otherwise stated. 


\section{Introduction}

Primary Sjögren's syndrome (pSS) is a systemic autoimmune disease that is characterised by mouth and eye dryness as well as fatigue and pain. Systemic manifestations occur in $20-40 \%$ of patients $[1,2]$. B lymphocytes play a crucial role in the pathogenesis of the disease in their capacity to secrete autoantibodies and cytokines or to present autoantigens.

Increased expression of the cytokine B-cell activating factor (BAFF), also called B-lymphocyte stimulator [3], is involved in the pathogenic mechanism of B-cell activation. BAFF plays a crucial role in B-cell maturation, plasma cell survival, antibody response promotion and immunoglobulin (Ig) class-switching recombination $[3,4]$. Its involvement in the pathogenesis of autoimmune diseases and lymphomagenesis is demonstrated by BAFF-transgenic mice that have autoimmune diseases mimicking systemic lupus erythematosus (SLE) and pSS and a rate of B-cell lymphoma twice that of control mice [4]. Patients with SLE and pSS have elevated serum levels of BAFF $[5,6]$, and serum levels of BAFF correlate with autoantibody levels [6-8] and have been found to be associated with pSS-associated lymphoproliferative complications $[9,10]$.

Therefore, targeting B-cell activation and BAFF in the setting of pSS seems appealing. Belimumab is the first marketed anti-BAFF monoclonal antibody. It was recently approved for treatment of SLE on the basis of two phase III studies that showed positive results $[11,12]$. Because pathophysiological studies also suggested an involvement of BAFF in the pathogenesis of pSS, we conducted the first open-label proof-of-concept study to evaluate the efficacy and safety of belimumab in pSS and found promising clinical results, including a decrease in disease activity as assessed using the European League Against Rheumatism Sjögren's Syndrome Disease Activity Index (ESSDAI) and in patients' symptoms as assessed using the European League Against Rheumatism Sjögren's Syndrome Patient Reported Index (ESSPRI).

As a part of the present trial, we addressed the changes in labial salivary gland (LSG) inflammation and serum lymphocyte pattern after belimumab therapy and identified predictors of response to treatment. We tried to find patient patterns corresponding to probable involved pathogenic pathways to make a first step toward personalised medicine in this polymorphic disease.

\section{Methods}

\section{Patients}

The Efficacy and Safety of Belimumab in Subjects with Primary Sjögren's Syndrome (BELISS) trial included patients in two identical studies conducted at the same time in two European centres, one in Paris, France, and one in Udine, Italy (ClinicalTrials.gov registration numbers
NCT01160666 and NCT01008982). Patients included fulfilled the American-European Consensus Group criteria for pSS [13], were positive for anti-Sjögren's syndrome antigen A or anti-Sjögren's syndrome antigen B antibodies and had, at the time of inclusion, at least one of the following three characteristics: systemic complications or persistent salivary gland enlargement, early disease $(\leq 5$ years from the beginning of symptoms) and/or presence of at least one biomarker of B-cell activation (increase in IgG level or free light chains or $\beta_{2}$-microglobulinemia, decrease in complement component 4 [C4] level, presence of cryoglobulinemia or monoclonal component). Other inclusion and exclusion criteria are reported elsewhere [14]. The patients received belimumab $10 \mathrm{mg} / \mathrm{kg}$ at week 0 (W0), W2 and W4 and then every 4 weeks to W24. Patients who responded to treatment at W28 were continued with belimumab monthly through W48, with a final evaluation scheduled at W52 (4 weeks after the last dose).

The present study is part of the BELISS trial and included analysis of changes in histological and serum lymphocyte patterns between W0 and W28 in the 15 patients at the French centre.

\section{Definitions of response to treatment}

Response to treatment was defined at W28 according to the composite primary endpoint, defined as follows: improvement in two of the following five parameters at W28: $\geq 30 \%$ reduction in dryness score on a visual analogue scale (VAS), $\geq 30 \%$ reduction in fatigue score on a VAS, $\geq 30 \%$ reduction in musculoskeletal pain score on a VAS, $\geq 30 \%$ reduction in systemic activity score on a VAS assessed by the physician, and/or $\geq 25 \%$ reduction in serum levels of any of several B-cell activation biomarkers (free light chains of Ig, $\beta_{2}$-microglobulin, monoclonal component, cryoglobulin, IgG) or $\geq 25 \%$ increase in C4 level.

Systemic response was also assessed at W28 and was defined as a decrease of $\geq 3$ points in ESSDAI score [15] in accordance with its minimal clinically important improvement [16]. Analyses of factors associated with response to treatment were based primarily on systemic response, which we considered the most robust way to define relevant improvement.

\section{BAFF assessment}

BAFF was measured at baseline, before the first belimumab dose, using an enzyme-linked immunosorbent assay (Quantikine kit; R\&D Systems, Minneapolis, MN, USA).

\section{Flow cytometry}

Subtype lymphocyte counts for T, B and natural killer (NK) cells were obtained by flow cytometry at W0, W4, W12 and W28. The results are expressed in absolute 
value (number of cells per cubic millimetre of blood). A blood sample of $200 \mu \mathrm{l}$ was used for phenotyping subsets of $\mathrm{CD} 19^{+}$with the following antibodies CD19 peridininchlorophyll protein (PerCP, clone 4GT, catalogue number 345778; BD Biosciences, San Jose, CA, USA), IgD fluorescein isothiocyanate (catalogue number H15501; Invitrogen, Carlsbad, CA, USA) and CD27 allophycocyanin (clone L128, catalogue number 337169; BD Biosciences). After staining, the blood sample was fixed (Lyse/fix solution; $\mathrm{BD}$ Biosciences) and cells were acquired on a $\mathrm{BD}$ FACSCalibur flow cytometer (BD Biosciences).

Among $\mathrm{B}$ cells, the following subtypes were analysed: naïve $\left(\mathrm{CD} 27^{-} \mathrm{IgD}{ }^{+}\right) \mathrm{B}$ cells, memory $\left(\mathrm{CD} 27^{+}\right) \mathrm{B}$ cells and their subtypes (switched $\left[\mathrm{CD}^{2} 7^{+} \operatorname{IgD}{ }^{-}\right]$and unswitched $\left.\left[\mathrm{CD} 27^{+} \operatorname{IgD}{ }^{+}\right]\right)$.

\section{Histological assessment}

Minor LSG biopsy samples were obtained at W0 and W28. Samples of LSGs were fixed in alcohol, acetic acid and formaldehyde solution and embedded in paraffin wax for histological study. All samples were analysed by the same pathologist (TL).

The following parameters were analysed: the focus score, the B-cell/T-cell ratio in the foci, BAFF expression in the foci and the NK infiltrate inside and outside the foci. The focus score was measured after haematoxylin eosin staining and was expressed as the number of foci (50 lymphocytes) per $4 \mathrm{~mm}^{2}$. The focus score was considered abnormal if it was $\geq 1$. B cells and $T$ cells were identified after CD20 (clone L26; DakoCytomation, Glostrup, Denmark) and CD3 (clone F.7.2.38; DakoCytomation) staining, respectively. The $\mathrm{B}$-cell/T-cell ratio was estimated in foci and expressed as the proportion of $B$ cells to T cells. BAFF expression was measured after incubation with a rat anti-human BAFF antibody called Buffy-2 (Enzo Life Sciences, Villeurbanne, France) and expressed as the proportion of BAFF-expressing cells inside the foci, regardless to their origin (B or T cells). NK cell infiltration was analysed after incubation with mouse anti-human NKP46/NCR1 antibody (R\&D Systems) inside and around the foci and was expressed as the number of NK cells per square millimetre as previously described [17].

\section{Ethics}

The study protocol was approved by the French ethics committee protection of humans in biomedical research and the French agency for the safety of medicine and health products. The study was conducted according to the current regulations of the International Conference on Harmonisation guidelines and the principles of the Declaration of Helsinki. All patients provided written informed consent before participating in any protocolspecific procedures.

\section{Statistical analyses}

Categorical variables are described with numbers (percentages). Quantitative variables are described with the median (interquartile range).

To analyse changes between W0 and W28, values were compared using Wilcoxon's signed-rank test for quantitative variables and McNemar's test for categorical variables.

To identify predictive factors of response to treatment, baseline lymphocyte counts and histological parameters were compared between responders and non-responders, using a Kruskal-Wallis test for quantitative variables and $x^{2}$ or Fisher's exact test for categorical variables.

For all statistical analyses, a $p$ value $<0.05$ was considered statistically significant. Data analysis was carried out with SAS 9.3 for Windows software (SAS Institute, Cary, NC, USA).

\section{Results}

\section{Patients}

All 15 patients were women. Their median age was 44 (36.5-63.5) years. Their median disease duration was 1 (0.5-6.5) year, and their median duration of symptoms was $6.5(4-12.5)$ years. Their characteristics are reported in Table 1.

Among the 15 patients, 8 had salivary gland swelling at the time of inclusion and 11 had other systemic complications, such as articular involvement $(\mathrm{n}=6)$, pulmonary involvement $(n=2)$, muscular involvement $(n=1)$, peripheral neuropathy $(\mathrm{n}=1)$, renal tubular acidosis $(\mathrm{n}=1)$ and autoimmune thrombocytopenia $(n=1)$.

\section{Belimumab induced incomplete B-cell depletion mainly linked to a dramatic decrease of naïve $B$ cells}

The available T, B and NK cell fluorescence-activated cell-sorting analysis data allowed the evaluation of 13 patients at baseline and comparisons between W0 and W28 in 11 patients. Regarding B-cell subtypes, data were available at baseline for nine patients and for comparison between W0 and W28 for eight patients.

After belimumab treatment, the median total lymphocyte count (1346 [895-2069] at W0 vs 1471 [905-1847] at W28; $\mathrm{n}=11)$, T cell count (902 [689-1655] at W0 vs 1152 [697-1367] at W28; $\mathrm{n}=11), \mathrm{CD} 4(690$ [471-890] at W0 vs 724 [438-923] at W28; $\mathrm{n}=11$ ) or CD8 T cells (336 [135-541] at W0 vs 388 [185-544] at W28; $\mathrm{n}=11$ ) did not change significantly (Fig. 1a).

By contrast, there was a significant increase in the number of NK cells (145 [104-179] at W0 vs 184 [109-273] at W28, $\mathrm{n}=11 ; p=0.032$ ) (Fig. 1c). This number did not differ according to the presence of systemic complications or glandular involvement.

Conversely, we found a decrease in B lymphocytes $\left(\mathrm{CD} 19^{+}\right)$. This decrease was observed as soon as W4 
Table 1 Baseline characteristics of patients

\begin{tabular}{ll}
\hline & All patients $(\mathrm{N}=15)$ \\
\hline Age, yr, median [IQR] & $44[36.5-63.5]$ \\
Female sex (\%) & $15(100.0 \%)$ \\
Disease duration, yr, median [IQR] & $1[0.5-6.5]$ \\
Whole unstimulated salivary flow $(<0.1 \mathrm{ml} / \mathrm{min})$ & $12(80 \%)$ \\
Schirmer's test $\leq 5 \mathrm{~mm}$ & $10(66.7 \%)$ \\
Focus score $\geq 1$ & $12(80 \%)$ \\
Baseline focus score, median [IQR] & $1.6[1-2.4]$ \\
Anti-SSA antibodies & $14(93.3 \%)$ \\
Anti-SSB antibodies & $10(66.7 \%)$ \\
Current background medication & \\
Corticosteroids & $4(26.7 \%)$ \\
Hydroxychloroquine & $5(33.3 \%)$ \\
Methotrexate & $0(0 \%)$ \\
Reason for inclusion & \\
Systemic complications & $11(73.3 \%)$ \\
Recent-onset disease & $4(26.7 \%)$ \\
Increase in B-cell biomarker values & $11(73.3 \%)$ \\
ESSDAl score (0-123), median [IQR] & $7[3-11]$ \\
ESSPRI score (0-10), median [IQR] & $6.33[6-7.33]$ \\
\hline Anti-sSA ant-Sjogen's syndrome & \\
\hline
\end{tabular}

Anti-SSA anti-Sjögren's syndrome antigen A antibodies, anti-SSB anti-Sjögren's syndrome antigen $B$ antibodies, ESSDAl European League Against Rheumatism Sjögren's Syndrome Disease Activity Index, ESSPRI European League Against Rheumatism Sjögren's Syndrome Patient Reported Index, IQR Interquartile range (i.e., the first evaluation after belimumab initiation) and persisted during the whole treatment duration (189 [31-296] W0 vs 81 [23-103] to W28, $\mathrm{n}=11$; $p=0.01$ ) (Fig. 1b).

This decrease primarily involved $\mathrm{CD}^{-} 7^{-} \mathrm{IgD}^{+}$naïve $\mathrm{B}$ cells (151 [24-186] at W0 vs 10 [6-40] at W28, $\mathrm{n}=9$; $p=0.008)$. There was no significant change in the total number of $\mathrm{CD} 27^{+}$memory B cells (39.5 [10.1-53.2] at W0 vs 47.7 [19.1-64.9] at W28, $\mathrm{n}=9 ; p=0.074)$ or $\mathrm{CD}^{2} 7^{+} \mathrm{IgD}^{+}$ unswitched memory B cells (8.8 [3.4-28.9] at W0 vs 15.7 [6.6-28.8] at W28, $\mathrm{n}=9 ; p=0.36$ ), but there was a slight increase in the number of $\mathrm{CD} 27^{+} \mathrm{IgD}{ }^{-}$switched memory $\mathrm{B}$ cells at W28 (19.6 [6.7-30.3] at W0 vs 35.8 [12.5-38.2] at W28; $p=0.019$ ) (Fig. 2).

\section{Belimumab therapy induces decrease of BAFF expression and $\mathrm{B}$-cell/T-cell ratio in salivary glands}

Minor LSG samples were obtained for all 15 patients at both W0 and W28. All samples were analysed for estimating focus and Chisholm scores, but only data of 14 patients were analysed for specific staining Fig. 3.

At inclusion, lymphocytic sialadenitis with a focus score $>1$ was observed in 12 (80\%) of 15 patients, 5 of whom had a negative test at W28 ( $p=0.03)$. Overall, the median focus score decreased from $1.6(1-2.4)$ to 0.5 $(0-3)(p=0.39)$ and Chisholm score decreased from 4 $(3-4)$ to $2(1-4)(p=0.007)$.

The median B-cell/T-cell ratio decreased from 0.58 $(0.5-0.67)$ to $0.50(0.5-0.5) \quad(p=0.06)$. The presence of BAFF staining was detected in $11(78.6 \%)$ of 14 patients before belimumab treatment and in only $7(50.0 \%)$ of

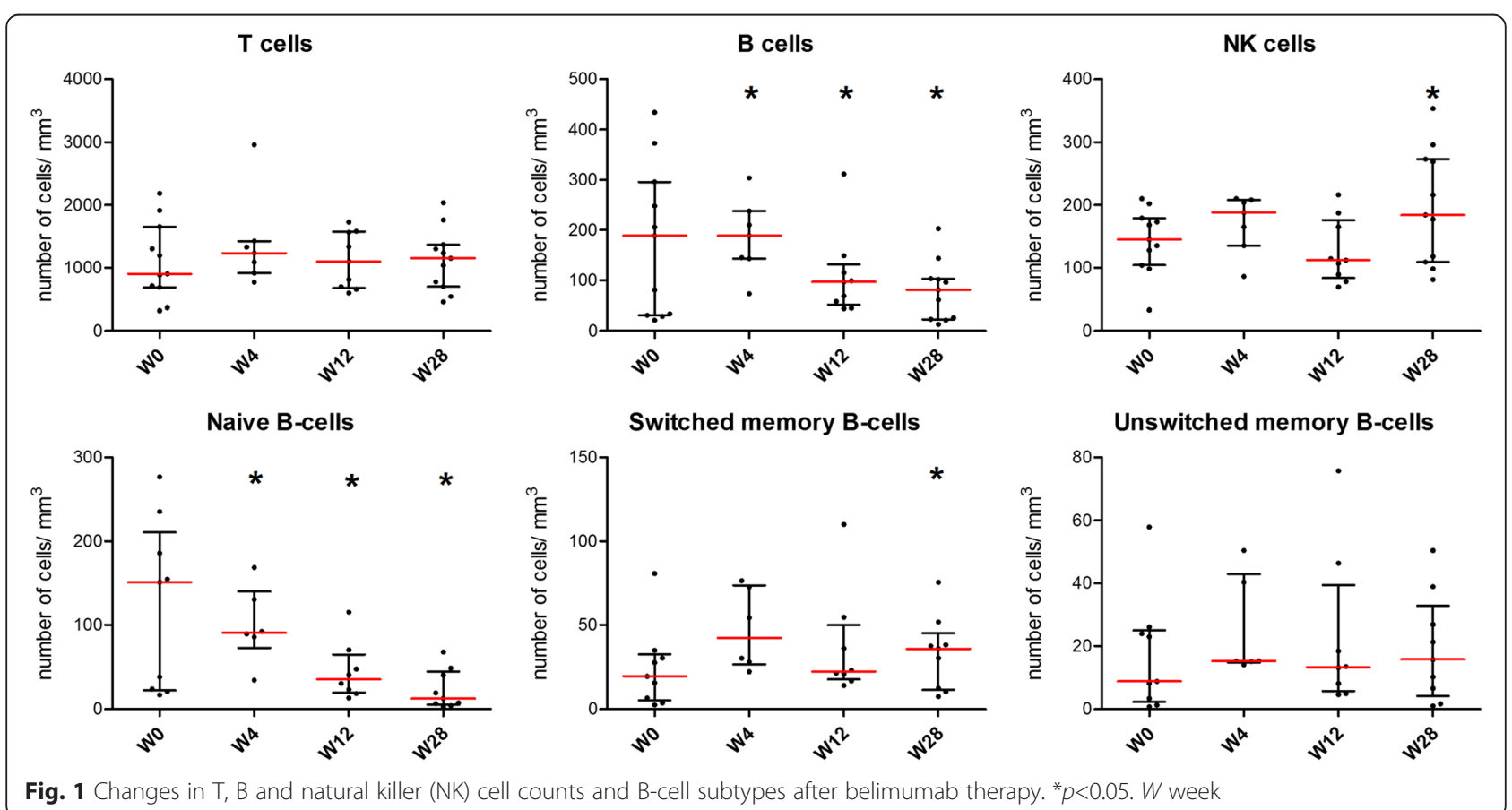




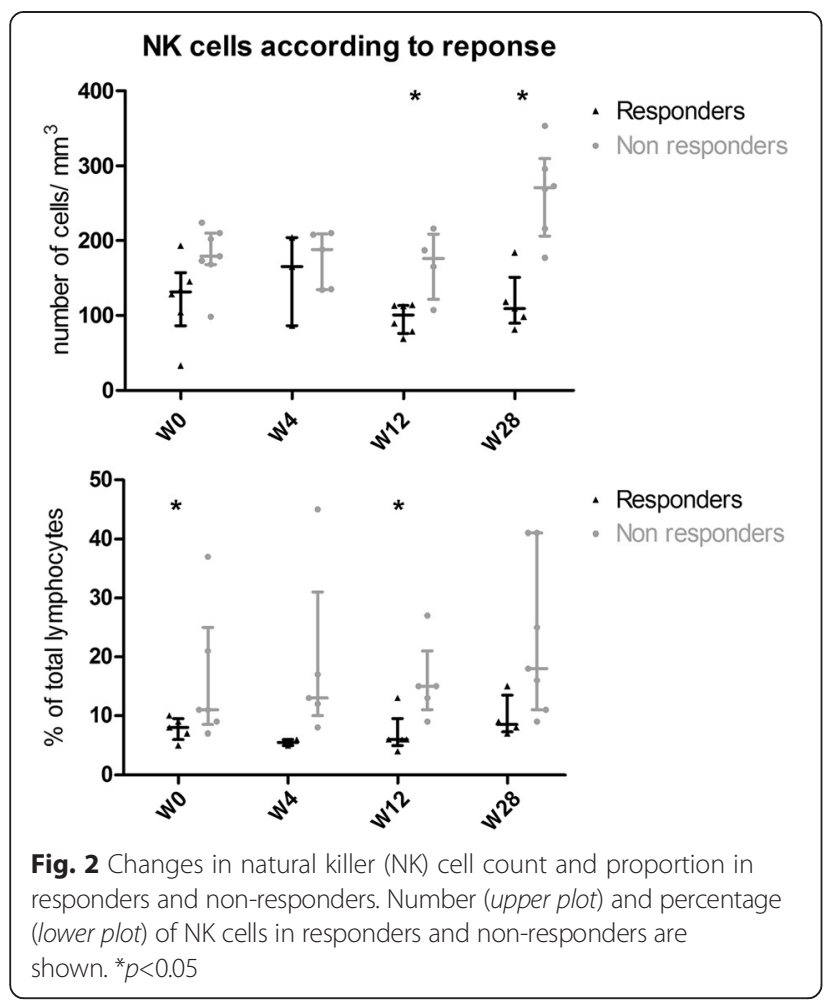

14 after belimumab therapy $(p=0.10)$. The median percentage of BAFF-positive cells in foci significantly decreased from $27.5 \%(10-40)$ to $5 \%(0-20)$ after belimumab therapy $(p=0.03)$. NKp46 staining revealed that NK cell infiltration was located predominantly in interstitia rather than in foci $\left(24.7\right.$ [21.4-38.9] vs $8.2 \mathrm{NKp} 46^{+}$ cells $/ \mathrm{mm}^{2}$ [4.2-10.0]; $\left.p=0.0003\right)$ and did not change after belimumab treatment. Of note, we observed a correlation, also found in one of our previous works, between the grading of focus score and the number of $\mathrm{NKp} 46^{+}$cells outside the inflammatory foci $\left(r^{2}=0.425\right.$; $p<0.0001)$.

\section{Low numbers of blood and salivary natural killer cells are} associated with a better response to belimumab

At W28, 6 (40 \%) of the 15 patients were responders according to the systemic definition (ESSDAI decrease of $\geq 3$ points) and 7 (53\%) achieved the composite primary endpoint, including the 6 systemic responders, showing a high concordance between these 2 criteria. The following analyses were based on systemic response.

Among the initial lymphocyte subpopulations, the only parameters associated with systemic response to belimumab were the percentage and number of NK cells $(8.5 \%[7-10]$ in responders vs $11 \%$ [9-21] in nonresponders, $p=0.04$; and 131 [104-145] in responders vs 179 cells $/ \mathrm{mm}^{3}[168-210]$ in non-responders, $p=0.06$ ). This was further confirmed at W12 $(p=0.02)$ and W28 $(p=0.04)$, when lower NK cell counts were observed in responders than in non-responders.

Also, change in NK cell absolute counts between W0 and W28 significantly differed between responders and non-responders. Even if they started with a higher number of NK cells, non-responder patients showed a further increase of NK cells compared with relative stability in responders $\left(+108 \mathrm{NK} / \mathrm{mm}^{3}[67-118]\right.$ vs $-23 / \mathrm{mm}^{3}$ $[-26,+56] ; p=0.017)$.

Neither baseline total nor B-cell subset cell counts, nor their variations with treatment, were associated with response to belimumab. Baseline serum BAFF levels also did not differ between responders and non-responders (790.3 pg/ml [692.1-927.4] vs $885.0 \mathrm{pg} / \mathrm{ml}$ [721.91100.5]; $p=0.79$ ).

Regarding histological findings, the only parameter associated with systemic response to belimumab was the importance of NK infiltrate in the periphery of the foci, which was lower in responders than in non-responders (median number of NK cells 20.6 [20.0-21.4] vs 30 $\mathrm{NKp} 46^{+}$cells $/ \mathrm{mm}^{2}$ [25.0-100.0]; $p=0.003$ ).

Neither the percentage of BAFF-positive cells nor Bcell/T-cell ratio was associated with the response to belimumab.

\section{Discussion}

In the present study, we assessed blood and LSG lymphocyte patterns before and after belimumab treatment in patients with pSS. Belimumab treatment was associated with significant and early incomplete B-cell depletion in peripheral blood involving the $\mathrm{CD}^{2} 7^{-} \mathrm{IgD}^{+}$ naïve B-cell subset. Analyses of LSG biopsies demonstrated a decrease in lymphocytic infiltration as assessed by focus and Chisholm scores. A significant decrease in the percentage of BAFF-positive cells within the foci was also observed. The only predictor of response to belimumab was a low count of blood and salivary NK cells.

Our study has two main limitations. First, it is an open study with no control arm for comparison. Second, the number of patients is small. Nevertheless, even in a small group of patients, we found interesting, significant results that reinforce their robustness and demonstrate that studying a small, well-phenotyped group of patients can be very informative.

The findings of the peripheral blood mononuclear cells are in line with what is known about the effect of belimumab therapy in patients with SLE. It is now established that belimumab leads to a decrease in naïve $B$ cells and to stability or an early increase in memory B cells $[18,19]$. We confirmed this interesting observation of an increase in memory B cells after belimumab treatment. We hypothesised that the magnitude of this increase in blood could reflect the importance of memory B-cell infiltration in the tissue as previously described 

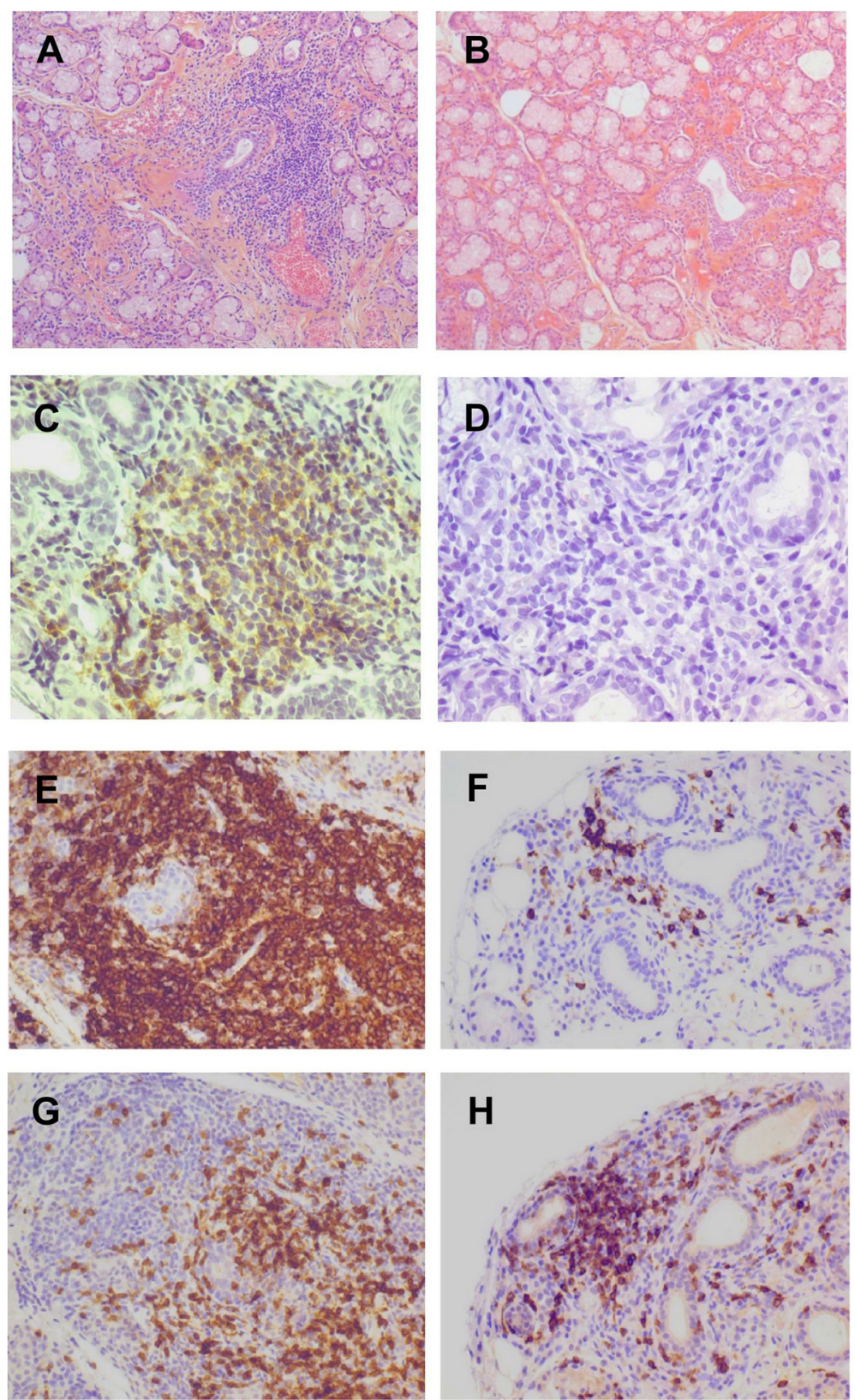

Fig. 3 Changes in histological pattern of salivary glands after belimumab therapy. Regression of lymphocytic infiltration after belimumab therapy ( $\mathbf{a}$ before and $\mathbf{b}$ after; hematein-eosin-saffron stain; original magnification, $\times 125$ ), major decrease of B-cell activating factor expression (c before and $\mathbf{d}$ after; Buffy-2 immunohistochemical stain, original magnification, $\times 320$.), dramatic decrease of B-cell infiltration (e before and $\mathbf{f}$ after; CD20 immunohistochemical stain; original magnification, $\times 250$ ), with slight decrease or stability of T-cell infiltration ( $\mathbf{g}$ before and $\mathbf{h}$ after; CD3 immunohistochemical stain; original magnification, $\times 250$ ), resulting in a trend for a decrease in B-cell/T-cell ratio

[20]. Indeed, the association of BAFF and chemokine (C$\mathrm{X}-\mathrm{C}$ motif) ligand 13 has been shown to be necessary for attracting memory B cells within germinal centres [21]. However, with the limitation of a small number of patients, we did not find any correlation between the magnitude of this increase and the response to treatment. To our knowledge, the monitoring of blood NK cells has not been studied in SLE. In this study, we found an effect of belimumab on NK cells whose absolute count increased with treatment.

We demonstrate for the first time that belimumab may induce changes in LSG infiltrate: decreases of lymphocytic infiltrate, Chisholm score and BAFF-expressing cells in the foci as well as a trend for a decreased B-cell/T-cell ratio. The decrease of BAFF-expressing cells is of particular interest but must be interpreted cautiously. It has been 
demonstrated in pSS that BAFF is secreted not only by monocytes and/or macrophages and dendritic cells but also by $\mathrm{T}$ and $\mathrm{B}$ cells and by salivary epithelial cells [22, 23]. However, the lowest number of BAFFexpressing cells could be only the consequence of the decrease of B cells expressing the BAFF receptor, with BAFF passively bound on its receptor and detectable by the anti-BAFF antibody.

The most interesting finding of the study is that, compared with non-responders, patients who responded to belimumab had a lower baseline number of NK cells, both in blood and in LSG at the periphery of the foci. We have previously shown that NK cells were present mainly in the salivary glands in this location and could play a role in pSS [17]. We have hypothesised that these NK cells could participate in the increased interferon (IFN)- $\gamma$ expression seen in a subset of patients with pSS. Indeed, the IFN signature observed in this disease may be divided in patients harbouring a restricted type I signature, a restricted type II signature or both [24]. On the one hand, type I IFN and B-cell activation could be linked, as supported by studies showing that IFN- $\alpha$ can induce BAFF [23, 25-27] and association between the type I IFN signature and B-cell biomarkers [28]. On the other hand, recent studies have highlighted the role of the interleukin-12-IFN- $\gamma$ axis in pSS pathogenesis [29]. Therefore, patients with a high baseline number of NK cells in the blood or in the glands might correspond to this second subset of patients having a high type II IFN signature, suggesting a disease not predominantly driven by $\mathrm{B}$ cells and thus less responsive to belimumab. Conversely, patients with low blood NK cell count or salivary gland infiltration might be more dependent on the type I IFN-B cell axis and may be good candidates for B-celltargeted therapy.

Interestingly, the lower NK cell count observed in responders compared with non-responders persisted throughout the study at W12 and W28, suggesting that this difference in NK cell numbers might really be the mirror of two types of pathogenesis in patients with pSS.

\section{Conclusions}

We found very interesting results suggesting an effect of belimumab on the glandular lymphoid infiltrate. One of the main results is the identification of the NK cells as an interesting predictive factor of the efficacy of belimumab, suggesting that two types of disease can be hypothesised in patients with pSS, the first one being NK cell- and type II IFN-driven and not responsive to B-cell-targeted therapy and the other being more Bcell-driven and more responsive to belimumab therapy. If the effectiveness of belimumab is confirmed in patients with pSS in randomised controlled studies, our findings could represent a first step toward personalised medicine for patients with pSS.

\section{Abbreviations}

Anti-SSA: anti-Sjögren's syndrome antigen A antibodies; anti-SSB: antiSjögren's syndrome antigen B antibodies; BAFF: B-cell activating factor; BELISS trial: Efficacy and Safety of Belimumab in Subjects With Primary Sjögren's Syndrome; C4: Complement component 4; ESSDAI: European League Against Rheumatism Sjögren's Syndrome Disease Activity Index; ESSPRI: European League Against Rheumatism Sjögren's Syndrome Patient Reported Index; IFN: Interferon; Ig: Immunoglobulin; IQR: Interquartile range; LSG: Labial salivary gland; pSS: Primary Sjögren's syndrome; SLE: Systemic lupus erythematosus; VAS: Visual analogue scale; W: Week.

\section{Competing interests}

XM received honoraria from GlaxoSmithKline. The other authors declare that they have no competing interests.

\section{Authors' contributions}

XM participated to conception and design, data collection, analysis, interpretation, drafting, critical reviewing, and final approval of the manuscript. RS participated to conception and design, data collection, analysis, interpretation, drafting, critical reviewing, and final approval of the manuscript. GN participated to data collection, analysis, interpretation, drafting, critical reviewing, and final approval of the manuscript. PR participated to conception and design, data collection critical reviewing, and final approval. TL participated to data collection, critical reviewing, and final approval. HHC participated to data collection critical reviewing, and final approval. FD participated to data collection critical reviewing, and final approval. RB participated to data collection critical reviewing, and final approval. MB participated to data collection critical reviewing, and final approval. VPC participated to data collection critical reviewing, and final approval. YT participated to data collection critical reviewing, and final approval.

\section{Acknowledgements}

This BELISS study was sponsored by AP-HP (Assistance Publique-Hopitaux de Paris) and by the Azienda Ospedaliero Universitaria "Santa Maria della Misericordia", Udine, Italy. It was supported by an unrestricted research grant from Human Genome Sciences/GlaxoSmithKline. Human Genome Sciences/GlaxoSmithKline did not have any role in the design, conduct, interpretation or reporting of the study. All data of major outcomes are available on request.

\section{Author details}

${ }^{1}$ Université Paris-Sud, Center of Research on Immunology of Viral and Autoimmune diseases (IMVA), INSERM U1184, Le Kremlin Bicêtre, France. ${ }^{2}$ Université Paris-Sud, Assistance Publique-Hôpitaux de Paris (AP-HP), Service de Rhumatologie, Hôpitaux Universitaires Paris-Sud, Hôpital Bicêtre, 78 rue du Général Leclerc, 94275 Le Kremlin Bicêtre, France. ${ }^{3}$ Université Paris-Sud, Assistance Publique-Hôpitaux de Paris (AP-HP), Service d'anatomopathologie, Hôpitaux Universitaires Paris-Sud, Le Kremlin Bicêtre, France. ${ }^{4}$ Université Paris-Sud, Assistance Publique-Hôpitaux de Paris (AP-HP), Laboratoire d'immunologie, Hôpitaux Universitaires Paris-Sud, Le Kremlin Bicêtre, France. ${ }^{5}$ Université Paris Descartes, AP-HP, Hôtel-Dieu Hospital, Centre de Recherche Épidémiologie et Statistique Sorbonne Paris Cité (CRESS-UMR1153), Paris, France. ${ }^{6}$ Institut de Cancérologie Gustave Roussy Cancer Campus (GRCC), INSERM U1015, GRCC, 475 rur Edouard Vaillant, 94805 Villejuif, France.

Received: 7 April 2015 Accepted: 10 August 2015

Published online: 04 September 2015

\section{References}

1. Tzioufas AG, Vlachoyiannopoulos PG. Sjogren's syndrome: an update on clinical, basic and diagnostic therapeutic aspects. J Autoimmun. 2012;39:1-3.

2. García-Carrasco M, Ramos-Casals M, Rosas J, Pallarés L, Calvo-Alen J, Cervera R, et al. Primary Sjögren syndrome: clinical and immunologic disease patterns in a cohort of 400 patients. Medicine (Baltimore). 2002:81:270-80.

3. Schneider P, Mackay F, Steiner V, Hofmann K, Bodmer JL, Holler N, et al. BAFF, a novel ligand of the tumor necrosis factor family, stimulates B cell growth. J Exp Med. 1999;189:1747-56. 
4. Mackay F, Woodcock SA, Lawton P, Ambrose C, Baetscher M, Schneider P, et al, Mice transgenic for BAFF develop lymphocytic disorders along with autoimmune manifestations. J Exp Med. 1999;190:1697-710.

5. Stohl W, Metyas S, Tan SM, Cheema GS, Oamar B, Xu D, et al. B lymphocyte stimulator overexpression in patients with systemic lupus erythematosus: longitudinal observations. Arthritis Rheum. 2003;48:3475-86

6. Mariette X, Roux S, Zhang J, Bengoufa D, Lavie F, Zhou T, et al. The level of BLyS (BAFF) correlates with the titre of autoantibodies in human Sjögren's syndrome. Ann Rheum Dis. 2003;62:168-71.

7. Petri M, Stohl W, Chatham W, McCune WJ, Chevrier M, Ryel J, et al. Association of plasma B lymphocyte stimulator levels and disease activity in systemic lupus erythematosus. Arthritis Rheum. 2008;58:2453-9.

8. Carter LM, Isenberg DA, Ehrenstein MR. Elevated serum BAFF levels are associated with rising anti-double-stranded DNA antibody levels and disease flare following B cell depletion therapy in systemic lupus erythematosus. Arthritis Rheum. 2013;65:2672-9.

9. Gottenberg JE, Seror R, Miceli-Richard C, Benessiano J, Devauchelle-Pensec $V$, Dieude $P$, et al. Serum levels of $\beta_{2}$-microglobulin and free light chains of immunoglobulins are associated with systemic disease activity in primary Sjögren's syndrome: data at enrollment in the prospective ASSESS cohort. PLoS One. 2013;8:e59868.

10. Quartuccio L, Salvin S, Fabris M, Maset M, Pontarini E, Isola M, et al. BLyS upregulation in Sjögren's syndrome associated with lymphoproliferative disorders, higher ESSDAI score and B-cell clonal expansion in the salivary glands. Rheumatology (Oxford). 2013;52:276-81.

11. Furie R, Petri M, Zamani O, Cervera R, Wallace DJ, Tegzova D, et al. A phase III, randomised, placebo-controlled study of belimumab, a monoclonal antibody that inhibits B lymphocyte stimulator, in patients with systemic lupus erythematosus. Arthritis Rheum. 2011;63:3918-30.

12. Navarra SV, Guzmán RM, Gallacher AE, Hall S, Levy RA, Jimenez RE, et al. Efficacy and safety of belimumab in patients with active systemic lupus erythematosus: a randomised, placebo-controlled, phase 3 trial. Lancet. 2011;377:721-31.

13. Vitali C, Bombardieri S, Jonsson R, Moutsopoulos HM, Alexander EL, Carsons SE, et al. Classification criteria for Sjögren's syndrome: a revised version of the European criteria proposed by the American-European Consensus Group. Ann Rheum Dis. 2002;61:554-8.

14. Mariette X, Seror R, Quartuccio L, Baron G, Salvin S, Fabris M, et al. Efficacy and safety of belimumab in primary Sjögren's syndrome: results of the BELISS open-label phase II study. Ann Rheum Dis. 2015;74:526-31.

15. Seror R, Ravaud P, Bowman SJ, Baron G, Tzioufas A, Theander E, et al. EULAR Sjögren's Syndrome Disease Activity Index: development of a consensus systemic disease activity index for primary Sjögren's syndrome. Ann Rheum Dis. 2010;69:1103-9.

16. Seror R, Bootsma H, Saraux A, Bowman SJ, Theander E, Brun JG, et al. Defining disease activity states and clinically meaningful improvement in primary Sjögren's syndrome with EULAR primary Sjögren's syndrome disease activity (ESSDAI) and patient-reported indexes (ESSPRI). Ann Rheum Dis. 2014 [Epub ahead of print] PubMed PMID: 25480887. doi:10.1136/annrheumdis-2014-206008.

17. Rusakiewicz S, Nocturne G, Lazure T, Semeraro M, Flament C, Caillat-Zucman S, et al. NCR3/NKp30 contributes to pathogenesis in primary Sjögren's syndrome. Sci Transl Med. 2013;5:195ra196.

18. Stohl W, Hiepe F, Latinis KM, Thomas M, Scheinberg MA, Clarke A, et al. Belimumab reduces autoantibodies, normalizes low complement levels, and reduces select $B$ cell populations in patients with systemic lupus erythematosus. Arthritis Rheum. 2012;64:2328-37.

19. Jacobi AM, Huang W, Wang T, Freimuth W, Sanz I, Furie R, et al. Effect of long-term belimumab treatment on B cells in systemic lupus erythematosus: extension of a phase II, double-blind, placebo-controlled, dose-ranging study. Arthritis Rheum. 2010;62:201-10.

20. Hansen A, Odendahl M, Reiter K, Jacobi AM, Feist E, Scholze J, et al. Diminished peripheral blood memory $B$ cells and accumulation of memory $B$ cells in the salivary glands of patients with Sjögren's syndrome. Arthritis Rheum. 2002;46:2160-71.

21. Badr G, Borhis G, Lefevre EA, Chaoul N, Deshayes F, Dessirier V, et al. BAFF enhances chemotaxis of primary human $B$ cells: a particular synergy between BAFF and CXCL13 on memory B cells. Blood. 2008;111:2744-54.

22. Daridon C, Devauchelle V, Hutin P, Le Berre R, Martins-Carvalho C, Bendaoud $B$, et al. Aberrant expression of BAFF by $B$ lymphocytes infiltrating the salivary glands of patients with primary Sjögren's syndrome. Arthritis Rheum. 2007;56:1134-44.

23. Lavie F, Miceli-Richard C, Ittah M, Sellam J, Gottenberg JE, Mariette X. B-cell activating factor of the tumour necrosis factor family expression in blood monocytes and T cells from patients with primary Sjögren's syndrome. Scand J Immunol. 2008:67:185-92.

24. Hall JC, Casciola-Rosen L, Berger AE, Kapsogeorgou EK, Cheadle C, Tzioufas AG, et al. Precise probes of type II interferon activity define the origin of interferon signatures in target tissues in rheumatic diseases. Proc Natl Acad Sci U S A. 2012;109:17609-14

25. Ittah M, Miceli-Richard C, Gottenberg JE, Sellam J, Eid P, Lebon P, et al. Viruses induce high expression of BAFF by salivary gland epithelial cells through TLR- and type-I IFN-dependent and -independent pathways. Eur J Immunol. 2008;38:1058-64.

26. Ittah M, Miceli-Richard C, Gottenberg JE, Lavie F, Lazure T, Ba N, et al. $B$ cell-activating factor of the tumor necrosis factor family (BAFF) is expressed under stimulation by interferon in salivary gland epithelial cells in primary Sjögren's syndrome. Arthritis Res Ther. 2006;8:R51.

27. Brkic Z, Maria NI, van Helden-Meeuwsen CG, van de Merwe JP, van Daele PL, Dalm VA, et al. Prevalence of interferon type I signature in CD14 monocytes of patients with Sjögren's syndrome and association with disease activity and BAFF gene expression. Ann Rheum Dis. 2013;72:728-35.

28. Emamian ES, Leon JM, Lessard CJ, Grandits M, Baechler EC, Gaffney PM, et al. Peripheral blood gene expression profiling in Sjögren's syndrome. Genes Immun. 2009;10:285-96.

29. Nocturne G, Mariette $X$. Advances in understanding the pathogenesis of primary Sjögren's syndrome. Nat Rev Rheumatol. 2013;9:544-56.

\section{Submit your next manuscript to BioMed Central and take full advantage of:}

- Convenient online submission

- Thorough peer review

- No space constraints or color figure charges

- Immediate publication on acceptance

- Inclusion in PubMed, CAS, Scopus and Google Scholar

- Research which is freely available for redistribution 